\title{
UafB is a serine-rich repeat adhesin of Staphylococcus saprophyticus that mediates binding to fibronectin, fibrinogen and human uroepithelial cells
}

\author{
Nathan P. King, ${ }^{1}$ Scott A. Beatson, ${ }^{1}$ Makrina Totsika, ${ }^{1}$ Glen C. Ulett, ${ }^{2}$ \\ Richard A. Alm, ${ }^{3}$ Paul A. Manning ${ }^{3} \dagger$ and Mark A. Schembri ${ }^{1}$ \\ ${ }^{1}$ School of Chemistry and Molecular Biosciences, The University of Queensland, Brisbane, \\ QLD 4072, Australia \\ ${ }^{2}$ School of Medical Sciences, Centre for Medicine and Oral Health, Griffith University Gold Coast \\ Campus, QLD 4222, Australia \\ ${ }^{3}$ AstraZeneca R\&D, Boston, Waltham, MA 02451, USA
}

Correspondence

Mark A. Schembri

m.schembri@uq.edu.au

\begin{abstract}
Staphylococcus saprophyticus is an important cause of urinary tract infection (UTI), particularly among young women, and is second only to uropathogenic Escherichia coli as the most frequent cause of UTI. The molecular mechanisms of urinary tract colonization by $S$. saprophyticus remain poorly understood. We have identified a novel $6.84 \mathrm{~kb}$ plasmid-located adhesin-encoding gene in S. saprophyticus strain MS1146 which we have termed uro-adherence factor B (uafB). UafB is a glycosylated serine-rich repeat protein that is expressed on the surface of $S$. saprophyticus MS1146. UafB also functions as a major cell surface hydrophobicity factor. To characterize the role of UafB we generated an isogenic uafB mutant in S. saprophyticus MS1146 by interruption with a group II intron. The uafB mutant had a significantly reduced ability to bind to fibronectin and fibrinogen. Furthermore, we show that a recombinant protein containing the putative binding domain of UafB binds specifically to fibronectin and fibrinogen. UafB was not involved in adhesion in a mouse model of UTI; however, we observed a striking UafB-mediated adhesion phenotype to human uroepithelial cells. We have also identified genes homologous to uafB in other staphylococci which, like uafB, appear to be located on transposable elements. Thus, our data indicate that UafB is a novel adhesin of $S$. saprophyticus that contributes to cell surface hydrophobicity, mediates adhesion to fibronectin and fibrinogen, and exhibits tropism for human uroepithelial cells.
\end{abstract}

Received 13 December 2010

Revised 5 January 2011

Accepted 13 January 2011

\section{INTRODUCTION}

Urinary tract infections (UTIs) are among the most common infectious diseases of humans and are a major cause of morbidity. In the USA alone, community-acquired UTIs are estimated to be the basis of seven million doctor visits each year (Schappert, 1999), with associated costs totalling \$1.6 billion annually (Foxman et al., 2000).

†Present address: Sacred Heart College Senior, 195-239 Brighton Road, Somerton Park, SA 5044, Australia.

Abbreviations: ECM, extracellular matrix; TEM, transmission electron microscopy; UPEC, uropathogenic E. coli; UTI, urinary tract infection.

The GenBank/EMBL/DDBJ accession number for the complete nucleotide sequence of $S$. saprophyticus plasmid pSSAP1 is FR687301.

A supplementary table, showing predicted protein-coding genes and other features of pSSAP1, is available with the online version of this paper.
Staphylococcus saprophyticus, a coagulase-negative staphylococcus, causes $5-20 \%$ of community-acquired UTIs (Hooton \& Stamm, 1997). S. saprophyticus is responsible for over $40 \%$ of UTIs in sexually active young women (Rupp et al., 1992) and is second only to Escherichia coli as the most common cause of UTIs in this subpopulation (Hovelius \& Mårdh, 1984). Symptoms of S. saprophyticus UTI are indistinguishable from those caused by E. coli (Rupp \& Archer, 1994), and recurrence is common, affecting $10-15 \%$ of infected women (Faro \& Fenner, 1998). Infection with S. saprophyticus is rarely associated with nosocomial UTI (Rupp \& Archer, 1994).

To establish infection of the urinary tract, bacteria must adhere to the epithelial cell lining (Mårdh et al., 1979). Most pathogens, including S. saprophyticus, express cell surface proteins which adhere to host cell molecules, including those of the extracellular matrix (ECM). A subset 
of Gram-positive surface molecules - cell wall-anchored proteins - share a common set of features which comprises an $\mathrm{N}$-terminal signal peptide, functional domains that may contain several serine-rich tandem repeats, and a hydrophobic cell wall-spanning sorting region at the $\mathrm{C}$ terminus that contains a conserved LPXTG motif and a charged tail (Navarre \& Schneewind, 1999). The extensive tandem repeats can be of varying sequence, size and frequency, and have been implicated in providing sites for O-linked glycosylation via the serine residues (Stephenson et al., 2002) and exposing the adhesive domain of the protein beyond the bacterial capsule (Shivshankar et al., 2009). The LPXTG motif is required for anchoring of the protein at the cell surface, and is cleaved by a sortase enzyme between the threonine and glycine residues during assembly of the peptidoglycan cell wall (Navarre \& Schneewind, 1999).

Currently, at least 11 serine-aspartate repeat (Sdr) proteins have been identified in staphylococci, including ClfA, ClfB and SdrC-SdrI (McCrea et al., 2000; Sakinç et al., 2006). Proteins in this family are adhesins and are characterized by the presence of a typical signal peptide, a non-repeat region (A region), often up to five long non-serine-rich tandem repeats (B-repeat regions), a C-terminal span of serine-aspartate tandem repeats, and an LPXTG anchor region.

Distinct from the Sdr proteins, serine-rich repeat proteins represent another family of Gram-positive cell wallanchored proteins, and have been best described in staphylococci and streptococci (Zhou \& Wu, 2009). The genes encoding these high-molecular-mass proteins are generally located together with additional genes that encode their own dedicated secretory and glycosylation systems. All of the characterized members of this group are adhesive glycoproteins (Zhou \& Wu, 2009). The Fap1 and GspB proteins are the best-characterized serine-rich repeat proteins and can be considered the prototypes of this family of adhesins. Fap1 of Streptococcus parasanguis binds to saliva-coated hydroxylapatite ( $\mathrm{Wu}$ et al., 1998) and GspB of Streptococcus gordonii mediates adhesion to human platelets, a precursor step in infective endocarditis (Bensing et al., 2004b). The GspB protein contains an atypical signal sequence that directs its export via the accessory Sec system (Bensing et al., 2007), while the non-repeat region flanked by the serine-rich repeats encodes the GspB binding domain (Takamatsu et al., 2005). Other serine-rich repeat proteins have also been shown to be virulence factors: SraP of Staphylococcus aureus (Siboo et al., 2005) and Hsa of Streptococcus gordonii (Bensing et al., 2004b) also bind to human platelets, while Srr-1 of Streptococcus agalactiae promotes blood-brain barrier penetration in a mouse meningitis model (van Sorge et al., 2009) and PsrP of Streptococcus pneumoniae binds to keratin 10 on lung cells and contributes to invasive pneumococcal disease (Shivshankar et al., 2009).

A core set of genes is conserved in every genome that contains serine-rich repeat protein-encoding genes (Zhou
\& Wu, 2009), consisting of $\sec A 2, \sec Y 2$, three accessory secretory protein genes (asp1-3) and two glycosyltransferase genes ( $g t f A, g t f B)$. The fimS accessory locus of Streptococcus salivarius contains two extra accessory secretory proteins (Zhou \& Wu, 2009). The secA2 gene is present in many pathogenic bacteria. The SecA2 protein of Streptococcus gordonii is an ATPase, like SecA (Bensing \& Sullam, 2009), but these proteins are distinct. In Streptococcus parasanguis it has been shown that polyclonal antibodies to SecA and SecA2 do not cross-react (Chen et al., 2006). The two glycosyltransferases are thought to form part of a glycosylation complex (Zhou \& Wu, 2009), which performs the protein glycosylation in the cytosol prior to export (Bensing et al., 2004a). The GspB protein consists of $10 \%(\mathrm{w} / \mathrm{w})$ carbohydrate (Bensing et al., 2004a), and this glycan modification is required for the stability and solubility of the protein (Takamatsu et al., 2004b). Protein glycosylation may also protect against extracellular proteolytic digestion (Upreti et al., 2003). Glycosylation of Fap1 contributes to a number of phenotypes, including adhesion (Peng et al., 2008). All of the streptococcal serinerich repeat protein accessory loci also contain additional glycosyltransferase $(g l y)$ and nucleotide sugar synthetase (nss) genes (Zhou \& Wu, 2009). These genes affect the glycoprotein carbohydrate composition but are not essential for glycosylation (Takamatsu et al., 2004a, b).

Only a small number of surface-associated proteins of $S$. saprophyticus have been described. The S. saprophyticus surface-associated protein ( $\mathrm{Ssp}$ ) has been identified as a lipase (Sakinç et al., 2005), and the autolysin/adhesin of $S$. saprophyticus (Aas) protein is a multifunctional autolysin, sheep erythrocyte haemagglutinin and fibronectin-binding adhesin (Gatermann \& Meyer, 1994; Hell et al., 1998). The S. saprophyticus ATCC 15305 genome sequence reveals the presence of the uro-adherence factor A (UafA) protein, which also agglutinates sheep erythrocytes and mediates binding to human uroepithelia (Kuroda et al., 2005). The serine-aspartate repeat protein I (SdrI) collagen- and fibronectin-binding adhesin is the most recently characterized S. saprophyticus surface protein (Sakinç et al., 2009, 2006). Among these surface-associated proteins, UafA and Aas are conserved in $100 \%$, Ssp in over $90 \%$, and SdrI in $5-10 \%$ of all S. saprophyticus strains so far tested (Kleine et al., 2010).

In this study, we have identified and characterized a novel serine-rich repeat glycoprotein (termed UafB) from $S$. saprophyticus. The uafB gene was shown to be located on a large plasmid and flanked by putative transposon sequences, suggesting mobility. We demonstrate that UafB is an adhesin that promotes cell surface hydrophobicity and mediates binding to fibronectin, fibrinogen and human bladder epithelial cells.

\section{METHODS}

Bacterial strains and plasmids. The bacterial strains and plasmids used in this study are listed in Table 1. Clinical S. saprophyticus 
Table 1. Strains and plasmids used in this study

\begin{tabular}{|c|c|c|}
\hline Strain or plasmid & Description & Reference or source \\
\hline \multicolumn{3}{|l|}{ E. coli strains } \\
\hline $\mathrm{DH} 5 \alpha$ & $\begin{array}{l}\mathrm{F}^{-} \phi 80 \mathrm{~d} l a c Z \Delta \mathrm{M} 15 \Delta(\text { lacZYA-argF }) \mathrm{U} 169 \text { deoR recA1 endA1 hsdR17 }\left(\mathrm{r}_{\mathrm{K}}^{-} \mathrm{m}_{\mathrm{K}}^{+}\right) \text {phoA } \\
\text { supE44 } \lambda^{-} \text {thi-1 gyrA96 relA1 }\end{array}$ & Grant et al. (1990) \\
\hline BL21 & $\mathrm{F}^{-} \quad o m p T h s d S_{\mathrm{B}}\left(\mathrm{r}_{\mathrm{B}}^{-} \mathrm{m}_{\mathrm{B}}^{-}\right) \mathrm{gal} d \mathrm{~cm}$ & Stratagene \\
\hline MS1616 & DH $5 \alpha$ containing pUafB & This study \\
\hline MS2017 & $\mathrm{DH} 5 \alpha$ containing $\mathrm{pUafBHis}$ & This study \\
\hline MS2777 & DH $5 \alpha$ containing pNK27 & This study \\
\hline \multicolumn{3}{|l|}{$\begin{array}{l}\text { S. saprophyticus } \\
\text { strains }\end{array}$} \\
\hline ATCC 15305 & Type strain (genome sequenced) & Kuroda et al. (2005) \\
\hline MS1146 & Clinical isolate & AstraZeneca \\
\hline MS2827 & MS1146, cured of endogenous pSSAP1 plasmid & This study \\
\hline pUafB & $\begin{array}{l}7653 \text { bp fragment, including uafB gene from MS1146, amplified with primers } 373 \\
\text { and } 434 \text { and cloned into pGEM-T Easy; } A^{r}{ }^{r}\end{array}$ & This study \\
\hline pUafBHis & $\begin{array}{l}1314 \text { bp uafB fragment, amplified with primers } 761 \text { and } 762 \text {, digested with EcoRI/XhoI and } \\
\text { cloned into EcoRI/XhoI-digested pBAD/HisB, with in-frame N-terminal } 6 \times \mathrm{His}_{\text {tag; }} \mathrm{Ap}^{\mathrm{r}}\end{array}$ & This study \\
\hline pNL9164 & E. coli/S. aureus TargeTron shuttle vector (temperature-sensitive); $\mathrm{Ap}^{\mathrm{r}} \mathrm{Em}^{\mathrm{r}}$ & Sigma \\
\hline pNK27 & $\begin{array}{l}\text { pNL9164 shuttle vector retargeted with primers 1412-1414, EBSU to knock out uafB } \\
\text { (TargeTron system); } \mathrm{Ap}^{\mathrm{r}} \mathrm{Em}^{\mathrm{r}}\end{array}$ & This study \\
\hline pNK37 & $\begin{array}{l}640 \text { bp uafB non-repeat region, amplified with primers } 2056 \text { and } 2057 \text { and cloned into the } \\
\text { SspI site of LIC E vector, with in-frame N-terminal } 6 \times \text { His tag and thioredoxin fusion; Ap }{ }^{r}\end{array}$ & This study \\
\hline
\end{tabular}

isolates were collected from the UCLA Medical Center, Los Angeles, CA, USA (five isolates including MS1146), the Christiana Hospital, Newark, DE, USA (five isolates), and Sullivan Nicolaides Pathology, Brisbane, Australia (65 isolates). S. saprophyticus ATCC 15305 has been described before (Kuroda et al., 2005). S. saprophyticus strains were cultured in/on brain heart infusion (BHI) broth/agar (Oxoid) supplemented with erythromycin $\left(10 \mu \mathrm{g} \mathrm{ml}^{-1}\right)$ as required. E. coli strains were cultivated in/on Luria-Bertani (LB) broth/agar supplemented with ampicillin $\left(100 \mu \mathrm{g} \mathrm{ml}^{-1}\right)$ or kanamycin $\left(50 \mu \mathrm{g} \mathrm{ml}^{-1}\right)$ as required.

DNA manipulations and genetic techniques. Plasmid DNA was isolated using the QIAprep Spin Miniprep kit (Qiagen). For staphylococcal strains, $100 \mu \mathrm{g} \mathrm{ml}{ }^{-1}$ recombinant lysostaphin (Ambi Products) was added to the resuspension buffer prior to incubation at $30^{\circ} \mathrm{C}$. Restriction endonucleases were used according to the manufacturer's specifications (New England Biolabs; NEB). $S$. saprophyticus genomic DNA was extracted as described by Wilson (2001), with the exception that overnight cultures were treated with lysostaphin and incubated for $1-2 \mathrm{~h}$ at $30{ }^{\circ} \mathrm{C}$ prior to the lysis step. PCR amplification of the uafB gene was performed using the Expand Long Template PCR system according to the manufacturer's instructions (Roche). PCR assays to determine the presence of uafB (primers 256 and 257), uafA (primers 258 and 259) and $s d r I$ (primers 260 and 261) were performed using Taq DNA polymerase (NEB) under the following conditions: 2 min at $94{ }^{\circ} \mathrm{C}, 25$ cycles of $15 \mathrm{~s}$ at $94{ }^{\circ} \mathrm{C}, 30 \mathrm{~s}$ at $55^{\circ} \mathrm{C}, 1 \mathrm{~min}$ at $72{ }^{\circ} \mathrm{C}$, one cycle of $7 \mathrm{~min}$ at $72{ }^{\circ} \mathrm{C}$, $4{ }^{\circ} \mathrm{C}$ hold. Primers were synthesized by Sigma and are listed in Table 2.

Sequencing and annotation of plasmid pSSAP1. A draft genome sequence of $S$. saprophyticus MS1146 was determined using a combination of Sanger sequencing and 454 GS-FLX (Roche) pyrosequencing. This revealed the presence of three plasmids, including the $u a f B$-containing plasmid pSSAP1. Assemblies were carried out using the Consed/Phrap/Phred software package (Gordon et al., 1998). In order to sequence across the extensive repeats in the $u a f B$ gene sequence, an Ez-Tn5 $<$ Kan-2> insertion kit (Epicentre) was employed. The $u a f B$ gene was PCR-amplified using primers 373 and 434, digested with HindIII/EcoRI and ligated into the HindIII/ EcoRI sites of pGEM-T Easy to generate plasmid pUafB. Plasmid pUafB was incubated with the transposon mixture as per the manufacturer's protocol. A portion of the transposition mixture was introduced into competent E. coli $\mathrm{DH} 5 \alpha$ cells, and the transformation mixture was plated onto LB agar containing kanamycin. Plasmid purification was performed from a random selection of the resultant transformant clones. The purified plasmids were digested with NotI and SphI to define the location of the transposon and to assist the sequence assembly process. The final pSSAP1 sequence was finished to Q40 standard with an average Sanger read depth of $\sim 16 \times$ coverage. Annotation of plasmid pSSAP1 was carried out using Artemis (Rutherford et al., 2000) and BLAST (Altschul et al., 1997) similarity searches of publicly available sequence databases.

Construction of S. saprophyticus MS1146 mutants. Strain MS2827 was isolated as a derivative of S. saprophyticus MS1146 that had reduced cell surface hydrophobicity due to loss of the uafBcontaining plasmid pSSAP1. Plasmid construct pNK27 (Table 1), specifically retargeted to the uafB gene of S. saprophyticus MS1146, was prepared using the Sigma TargeTron Gene Knockout system, as per the manufacturer's instructions. Briefly, optimal intron insertion sites and primer sequences (1412-1414, Table 2) were determined by the TargeTron online design site, followed by a retargeting PCR and cloning of the PCR product into the shuttle vector provided, 
Table 2. PCR primers used in this study

\begin{tabular}{|c|c|c|}
\hline Primer & Sequence $\left(5^{\prime}-3^{\prime}\right)$ & Description \\
\hline 256 & GAGGATTTAGGTTCAGCAATCG & uafB screen forward \\
\hline 257 & AAACCGTATCCCTGTTTAGCC & $u a f B$ screen reverse \\
\hline 258 & GTGCAACGAATACTGCGAAA & uafA screen forward \\
\hline 259 & CGTGTGCTCGTGTGTCTCTT & uafA screen reverse \\
\hline 260 & ACGCAGTAAGGAAGGCTCAA & $s d r I$ screen forward \\
\hline 261 & CTGACGGTTTAACTGCTTGG & $s d r I$ screen reverse \\
\hline 373 & ATTAAGCTTCAACATTATGTCTTAGCCTCTTTG & uafB cloning reverse \\
\hline 434 & GCATAGAATTCCAACAGAACCCGGCATAAAT & uafB cloning forward \\
\hline 761 & GCTCACTCGAGGAAAGCATCGGCAGTTATTG & $\begin{array}{l}\text { uafB fragment PCR for cloning into } \mathrm{pBAD} / \mathrm{HisB} \text {, for } \\
\text { antibody production, forward. Contains XhoI site } \\
\text { (underlined) }\end{array}$ \\
\hline 762 & GCTCGGAATTCGCTGTCCATGTAGTTGTTAAACC & $\begin{array}{l}\text { uafB fragment PCR for cloning into } \mathrm{pBAD} / \mathrm{HisB} \text {, for } \\
\text { antibody production, reverse. Contains EcoRI site } \\
\text { (underlined) }\end{array}$ \\
\hline 1011 & TTCTTTAGGTGATGAACATATCAGG & $\begin{array}{l}\text { Sequencing primer to check for correct } 350 \mathrm{bp} \text { retargeted } \\
\text { intron fragments for TargeTron }\end{array}$ \\
\hline 1412 & $\begin{array}{l}\text { AAAAAAGCTTATAATTATCCTTAAATC- } \\
\text { TCCTAAAAGTGCGCCCAGATAGGGTG }\end{array}$ & uafB TargeTron IBS \\
\hline 1413 & $\begin{array}{l}\text { CAGATTGTACAAATGTGGTGATAACAGA- } \\
\text { TAAGTCCTAAAAGTTAACTTACCTTTCTTTGT }\end{array}$ & uafB TargeTron EBS1d \\
\hline 1414 & $\begin{array}{l}\text { TGAACGCAAGTTTCTAATTTCGGTTAGAT- } \\
\text { TCCGATAGAGGAAAGTGTCT }\end{array}$ & uafB TargeTron EBS2 \\
\hline 2056 & TACTTCCAATCCAATGCGGATTTAGGTTCAGCAATCG & $\begin{array}{l}\text { uafB fragment PCR for cloning the non-repeat region } \\
\text { into LIC E vector, forward. Contains LIC extension } \\
\text { (underlined) }\end{array}$ \\
\hline 2057 & TTATCCACTTCCAATGTTATTCGCTTGTAGGATCCGTAAC & $\begin{array}{l}\text { uafB fragment PCR for cloning the non-repeat region } \\
\text { into LIC E vector, reverse. Contains LIC extension } \\
\text { (underlined) }\end{array}$ \\
\hline EBSU & CGAAATTAGAAACTTGCGTTCAGTAAAC & TargeTron EBS universal \\
\hline FUP & CGTTGTAAAACGACGGCCAG & M13 Universal forward \\
\hline RUP & AGGAAACAGCTATGACCATG & M13 Universal reverse \\
\hline
\end{tabular}

pNL9164 (Table 1). The construct was sequenced to verify correct inserts using primer 1011 (Table 2). The retargeted plasmid was then purified with a Qiagen Maxiprep kit and introduced into $S$. saprophyticus MS1146 by protoplast transformation, as described by Hell et al. (1998), followed by $\mathrm{CdCl}_{2}$ induction and colony PCR screening to identify the uafB knockout (MS1146uafB).

Purification of truncated UafB, rUafB ${ }_{\text {nrr }}$, antibody production and immunoblotting. For antiserum production, a 1308 bp segment from $u a f B$ was amplified with primers 761 and 762 (Table 2), digested with Xhol/EcoRI and ligated into XhoI/EcoRI-digested pBAD/HisB. The resultant plasmid (pUafBHis) contained base pairs 213-1520 of uaf $B$ fused to a $6 \times$ His encoding sequence. E. coli BL21 was transformed with plasmid pUafBHis and induced with $0.2 \%$ arabinose, and the resultant $6 \times$ His-tagged protein was purified using the Qiagen Ni-NTA Spin kit according to the manufacturer's instructions. Protein purity was assessed by SDS-PAGE analysis. Polyclonal anti-UafB serum was raised in rabbits by the Institute of Medical and Veterinary Sciences (South Australia) following a standard protocol. To construct the recombinant $\mathrm{rUafB}_{\text {nrr }}$ fusion protein, a $640 \mathrm{bp}$ segment of uafB encoding the non-repeat region (nrr) was amplified with primers 2056 and 2057 (Table 2). The PCR product was then inserted into a pET21a-based LIC vector. The construct (pNK37) contained base pairs 999-1638 of uafB fused to upstream $6 \times$ His and thioredoxin-encoding sequences. E. coli BL21 harbouring pNK37 was induced with $1 \mathrm{mM}$ IPTG, and the fusion protein was purified under native conditions using a Qiagen NiNTA Superflow column as per the manufacturer's instructions. The negative control protein $(6 \times$ His-thioredoxin, no uafB fusion $)$ was induced and purified in the same way. Buffer-exchanged recombinant proteins were analysed by SDS-PAGE and quantified using a bicinchoninic acid kit (Sigma). Staphylococcal cell lysates were prepared as follows: $10 \mathrm{ml}$ of overnight culture was pelleted by centrifugation, resuspended in $300 \mu$ lysostaphin buffer $(0.15 \mathrm{M}$ $\mathrm{NaCl}, 0.05 \mathrm{M}$ Tris/HCl, $\mathrm{pH}$ 8.0) containing recombinant lysostaphin $\left(100 \mu \mathrm{g} \mathrm{ml}^{-1}\right)$ and Benzonase endonuclease (Sigma, $\left.50 \mathrm{U}\right)$, and incubated for $1 \mathrm{~h}$ at $30^{\circ} \mathrm{C}$. The cells were then sonicated with a Branson sonicator (four times $10 \mathrm{~s}$ ) on ice. The sonicated cells were centrifuged, and the supernatant was removed, added to SDS-PAGE loading buffer and boiled for $5 \mathrm{~min}$. For immunoblotting, whole-cell lysates were subjected to SDS-PAGE using NuPAGE Novex 3-8\% Tris-acetate precast gels with NuPAGE Tris-acetate SDS running buffer, and subsequently transferred to PVDF microporous membrane filters using the iBlot dry blotting system as described by the manufacturer (Invitrogen). For the Western blot analysis, serum raised against $\mathrm{UafB}$ was used as primary serum and the secondary antibody was alkaline phosphatase-conjugated anti-rabbit IgG (A3687, Sigma). Sigma Fast BCIP/NBT (5-bromo-4-chloro-3-indolyl phosphate/nitro blue tetrazolium) was used as the substrate in the detection process. Glycoprotein detection was performed using a DIG Glycan Detection kit (Roche) as per the manufacturer's instructions. 
Microscopy and image analysis. Immunogold labelling and transmission electron microscopy (TEM) were performed essentially as described previously (Ulett et al., 2007a) but with some modifications. Cells were fixed with $4 \%$ paraformaldehyde in PBS ( $5 \mathrm{~min}$ ) prior to quenching. Anti-UafB serum was used undiluted as the primary antibody. Air-dried grids were negatively stained with $1 \%$ uranyl acetate before TEM analysis.

Cell surface hydrophobicity assay. The microbial adhesion to hydrocarbons (MATH) assay was performed essentially as described by Martin et al. (1989). Briefly, overnight cultures (10 ml) were pelleted by centrifugation, washed twice with saline, resuspended in $10 \mathrm{ml}$ saline and adjusted to $\mathrm{OD}_{600} 0.3$. In triplicate, $5 \mathrm{ml}$ bacterial suspensions were overlaid with $0.4 \mathrm{ml} \mathrm{n}$-hexadecane and mixed on a platform shaker at $37{ }^{\circ} \mathrm{C}$ (400 r.p.m., $15 \mathrm{~min}$ ). After $10 \mathrm{~min}$ equilibration at room temperature, the lower aqueous phase was aspirated and the $\mathrm{OD}_{600}$ measured. The hydrophobicity index (HPBI) was calculated as follows: [OD (initial)-OD (final)]/OD (initial). The results were analysed by ANOVA.

Human uroepithelial cell adhesion assays. T24 bladder epithelial cells (ATCC no. HTB-4) were maintained in McCoy's 5a modified medium (Gibco), with fetal bovine serum (FBS) added to a final concentration of $10 \%$. The interaction of S. saprophyticus MS1146, MS1146uafB and MS2827 with T24 epithelial cell monolayers was studied essentially as previously described (Valle et al., 2008). Briefly, wells were seeded with $1.1 \times 10^{5}$ cells in 24 -well tissue culture plates (eight replicates for each bacterial strain). Once cells were confluent $\left(1.2 \times 10^{6}\right.$ cells per well $)$, the culture medium was removed and cells were washed three times with PBS. Overnight bacterial cultures were diluted and grown to $\mathrm{OD}_{600} 0.55$, pelleted by centrifugation, washed three times with PBS and resuspended in 1:10 diluted McCoy's medium (without FBS). Bacteria $\left(6.6 \times 10^{6}\right.$ cells per well) were added to the T24 cell monolayers at an m.o.i. of 60 and incubated for $80 \mathrm{~min}$ at $37{ }^{\circ} \mathrm{C}$ in $5 \% \mathrm{CO}_{2}$. The inoculating dose of bacteria was confirmed by serial dilution and plating. Monolayers were washed four times with PBS to remove non-adherent bacteria. The remaining bacteria were released by eukaryotic cell lysis with $0.1 \%$ Triton X-100, and the number of adherent bacteria was determined by serial dilution and plating. The results were analysed by ANOVA. To test adhesion of the S. saprophyticus strains to fresh exfoliated uroepithelial cells, mid-stream urine was collected, pooled and centrifuged $(500 \mathrm{~g}, 15 \mathrm{~min})$ to harvest the uroepithelial cells. Overnight cultures of bacteria were pelleted by centrifugation and resuspended in a onetenth volume of PBS. The epithelial cells and bacteria were mixed in equal parts and incubated at $37^{\circ} \mathrm{C}, 175$ r.p.m. for $1 \mathrm{~h}$. The epithelial cells were washed four times with PBS $(500 \mathrm{~g}, 3 \mathrm{~min})$ and resuspended in PBS. Cells were examined using phase-contrast microscopy ( $\times 63$ magnification).

Immobilized fibronectin and fibrinogen adhesion assay. Microtitre plate (Nunc U96 Maxisorp) wells were coated with $2 \mu \mathrm{g}$ fibronectin, fibrinogen or BSA (Sigma) in $100 \mu \mathrm{l}$ PBS per well overnight at $4{ }^{\circ} \mathrm{C}$. Wells were then washed three times with $200 \mu \mathrm{l}$ PBS, quenched with $170 \mu \mathrm{l} 2 \% \mathrm{BSA}$ in PBS for $1 \mathrm{~h}$, and then washed twice with $200 \mu \mathrm{l}$ PBS before the addition of bacteria. Overnight bacterial cultures were washed and resuspended in PBS to a concentration of $1 \times 10^{9}$ c.f.u. $\mathrm{ml}^{-1}$. The microtitre plate was inoculated with the bacterial suspensions $(100 \mu \mathrm{l}$ cells per well $)$ and incubated for $2 \mathrm{~h}$ at $37^{\circ} \mathrm{C}$. For negative control wells, $100 \mu \mathrm{l}$ PBS was added instead of bacteria. The wells were washed three times with $200 \mu \mathrm{l} \mathrm{PBS}$ and the adherent cells were fixed with $150 \mu \mathrm{l} 25 \%$ aqueous formaldehyde for $30 \mathrm{~min}$ at room temperature. Wells were washed twice with $200 \mu \mathrm{l}$ PBS, stained with $150 \mu \mathrm{l} 0.1 \%$ crystal violet for $30 \mathrm{~min}$, washed again with water and incubated with $150 \mu \mathrm{l}$ ethanol/acetone $(80: 20)$ mixture for $30 \mathrm{~min}$ at room temperature with gentle agitation. $A_{570}$ measurements were obtained using a microtitre plate reader and results were analysed by ANOVA.

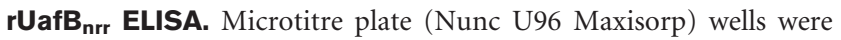
coated with $5 \mu \mathrm{g}$ fibronectin, fibrinogen and BSA (Sigma) in $100 \mu \mathrm{l}$ PBS overnight at $4{ }^{\circ} \mathrm{C}$. Wells were then washed twice with $200 \mu \mathrm{l}$ Trisbuffered saline, $0.1 \%$ Tween 20 (TBST), quenched with $150 \mu \mathrm{l}$ Trisbuffered saline (TBS), $1.5 \%$ BSA for $1 \mathrm{~h}$ and then washed three times with $200 \mu \mathrm{T}$ TBST. Recombinant $6 \times$ His-Trx $-\mathrm{UafB}_{\text {nrr }}$ and $6 \times$ His-Trx proteins were added at a concentration of $5 \mu \mathrm{M}$ (total volume of $100 \mu \mathrm{l}$ per well) and incubated for $1 \mathrm{~h}$ at room temperature. The wells were washed four times with TBST before the addition of $100 \mu \mathrm{l}$ $1: 2500$ mouse anti-polyhistidine antibodies (H1029, Sigma) diluted in TBS, $1.5 \%$ BSA. Plates were incubated for $1 \mathrm{~h}$ at room temperature, washed six times with TBST and then incubated with $100 \mu 11: 7500$ rabbit anti-mouse alkaline phosphatase-conjugated antibodies (A4312, Sigma) in TBS, $1.5 \%$ BSA for $1 \mathrm{~h}$ at room temperature. Wells were washed six times with TBST. A $1 \mathrm{mg} \mathrm{ml}^{-1}$ p-nitrophenyl phosphate (pNPP) (N2765, Sigma) substrate solution dissolved in $0.1 \mathrm{M}$ glycine, $1 \mathrm{mM} \mathrm{MgCl}_{2}, 1 \mathrm{mM} \mathrm{ZnCl}$ buffer, $\mathrm{pH}$ 10.4, was added and incubated at $37{ }^{\circ} \mathrm{C}$ for $30 \mathrm{~min}$. The reaction was stopped with $50 \mu \mathrm{l} 3 \mathrm{M} \mathrm{NaOH}$ and the $A_{405}$ was read with a microtitre plate reader. Mean values were compared using Student's $t$ test.

Mouse model of UTI. The mouse model of UTI was performed as previously described (Ulett et al., 2007b). Female C57BL/6 mice (9 weeks) were purchased from the University of Queensland Animal Facility. For colony counts, bladder and kidney homogenates, as well as the urine, were serially diluted in PBS and plated onto BHI agar. Means were compared by ANOVA.

\section{RESULTS}

\section{The surface hydrophobicity of S. saprophyticus MS1146 is mediated by a plasmid-encoded factor}

S. saprophyticus MS1146 possesses a high cell surface hydrophobicity index, a feature which is significantly different from the genome-sequenced S. saprophyticus ATCC 15305 (Fig. 1a). S. saprophyticus MS1146 contains three endogenous plasmids, and we hypothesized that a factor(s) encoded on one of these plasmids might be associated with this difference in hydrophobicity. We therefore screened a large number of $S$. saprophyticus MS1146 colonies obtained following repeated passaging in BHI medium for their cell surface hydrophobicity index. Using this approach, we identified one mutant (MS2827) that had significantly reduced hydrophobicity (Fig. 1a). Further analysis of MS2827 using PCR primers designed to target each individual plasmid revealed that it lacked one plasmid, which we have termed plasmid pSSAP1. Thus, our focus was targeted at the analysis of plasmid PSSAP1, and the identification and characterization of factors associated with cell surface hydrophobicity in S. saprophyticus MS1146.

\section{Bioinformatic analysis of plasmid pSSAP1}

Sequence analysis of the $66104 \mathrm{bp}$ plasmid pSSAP1 revealed the presence of 46 predicted protein-coding genes, eight pseudogenes or degenerate insertion sequence (IS) elements, and several repeat regions (Fig. 1b, Supplementary 
(a)
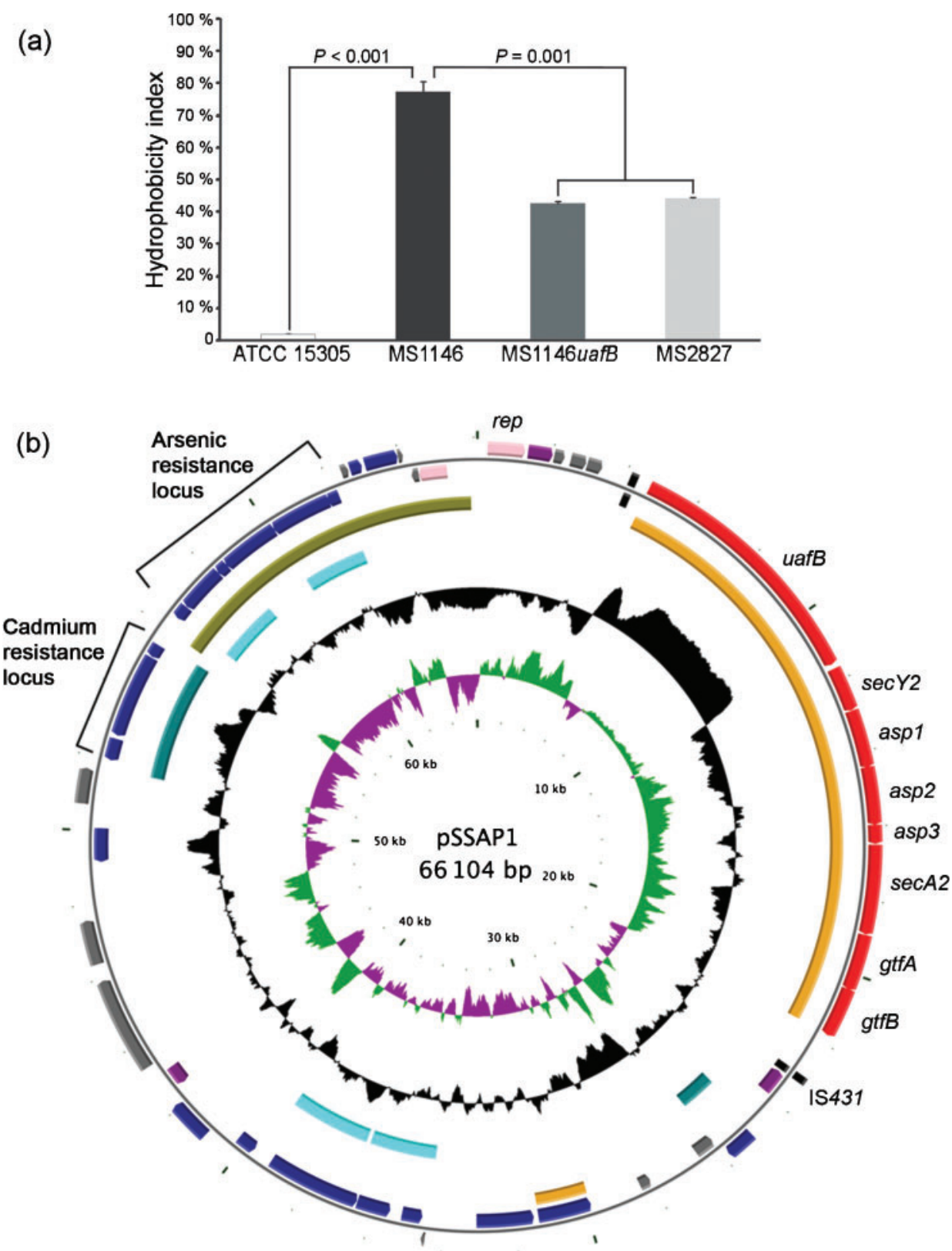

Fig. 1. (a) Cell surface hydrophobicity of S. saprophyticus ATCC 15305, MS1146, MS1146uafB and MS2827. Measurements were made using a two-phase aqueous-hydrocarbon system. The results are presented as the mean of three replicates +SEM from three independent experiments. A significant difference in cell surface hydrophobicity was observed between MS1146 and ATCC 15305 ( $P<0.001 ; t$ test) as well as between MS1146 and MS1146uafB/MS2827 ( $P=0.001$; ANOVA). (b) Genetic map of the S. saprophyticus MS1146 pSSAP1 plasmid. Arrows either side of the outer circle denote the protein-coding regions in the plasmid. The regions encoding uro-adherence factor B (uafB) and accessory genes, IS431, the rep replication initiation gene, the cadmium resistance loci $(c a d C A, c a d D)$ and arsenic resistance loci $(\operatorname{ars} A, \operatorname{ars} R B C)$ are labelled. Coding sequences are coloured according to predicted function: uafB or accessory gene, red; transposase or IS-related function, purple; plasmidrelated function, pink; other predicted function or conserved hypothetical protein, blue; hypothetical protein, grey. Inverted repeats formed by degenerate IS 4 elements either side of the uafB locus are shown as black bars. In the inner circles, arcs indicate regions longer than $1 \mathrm{~kb}$ of high nucleotide identity to other staphylococcal sequences: S. epidermidis SK30 plasmid SAP107A, 85-92\% identity (gold); S. saprophyticus ATCC 15303 pSSP1 (olive) and pSSP2, both >98\% identity (cyan); and the S. haemolyticus JCSC1435 genome sequence, 96-98\% identity (aqua) (accession nos G0900456, AP008935, AP008936 and AP006716). The two innermost circles represent deviation from the mean $\mathrm{G}+\mathrm{C}$ content (32.4\%) and GC-skew, respectively. Sizes are given in kilobase pairs (kb). 
Table S1). Like other staphylococcal plasmids, pSSAP1 has a mosaic structure with evidence of multiple insertions and deletions of discrete sequence blocks, many carrying genes for heavy metal resistance. For example, there is a high level of nucleotide sequence identity to the cadCA cadmium resistance and arsRBC arsenic resistance operons of $S$. aureus pI258 (Endo \& Silver, 1995; Nucifora et al., 1989). The most notable feature of pSSAP1 is the presence of a $17 \mathrm{~kb}$ cluster containing a novel gene encoding a serine-rich repeat adhesin (which we have termed uro-adherence factor B or uafB) and seven genes encoding a putative accessory expression system. The accessory expression genes are located immediately downstream of the $u a f B$ gene and putatively encode SecA2, SecY2, three accessory secretory proteins and two glycosyltransferases (Fig. 2a). This locus is located within a pair of $\sim 210$ bp inverted repeats formed from degenerate IS4 sequences (Fig. 1b). Immediately downstream of the left-hand inverted repeat is an intact IS431 transposase, which is often found encoded within SCCmec elements. Other genes encoded by pSSAP1 are hypothetical or have general functional predictions only (Fig. 1b, Supplementary Table S1). The remainder of this study aimed to characterize the function of UafB.

\section{Sequence analysis of UafB}

The $u a f B$ gene is highly repetitive in nature and required the use of an in vitro transposon mutagenesis strategy to complete its sequence. The uafB gene was PCR-amplified and cloned in pGEM-T Easy to generate plasmid pUafB. In vitro transposon mutagenesis was employed to generate a library of overlapping transposon mutants, which enabled sequencing across the repetitive region of the gene. This revealed that the $u a f B$ gene is an intact coding region of $6840 \mathrm{bp}$ in length. The size of the complete uafB gene sequence corresponded with that of the uafB PCR product (data not shown).

The unmodified UafB protein consists of 2279 amino acid residues (Fig. 2b). The $\mathrm{N}$ terminus contains an atypical

(a)

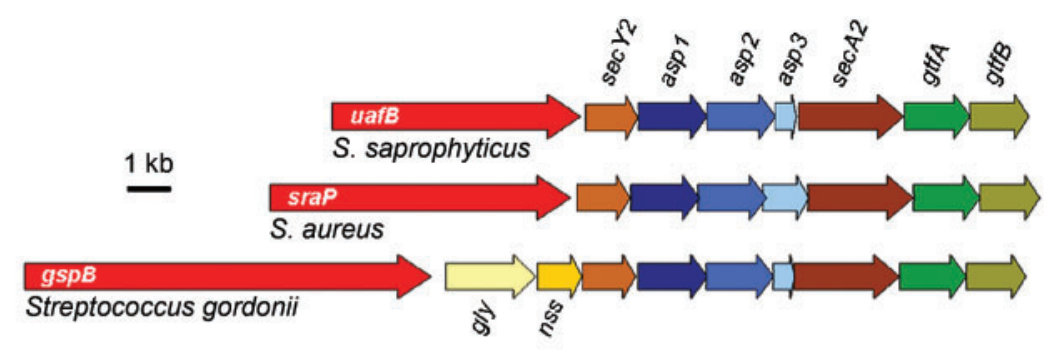

(b)

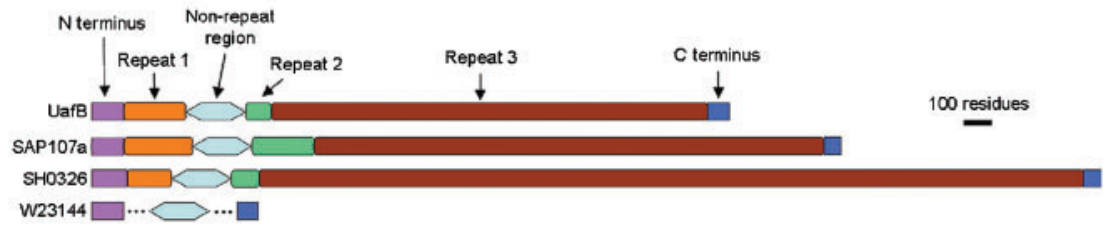

\begin{tabular}{lcccc}
\multicolumn{1}{l}{ (C) } & $\begin{array}{c}\text { S. saprophyticus } \\
\text { MS1146 (UafB) }\end{array}$ & $\begin{array}{c}\text { S. epidermidis } \\
\text { SAP107A }\end{array}$ & $\begin{array}{c}\text { S. haemolyticus } \\
\text { JCSC1435 }\end{array}$ & $\begin{array}{c}\text { S. epidermidis } \\
\text { W23144 }\end{array}$ \\
\hline N terminus & - & $69 \%$ & $53 \%$ & $93 \%$ \\
Repeat 1 & SKDSA(A/V)S(A/T/E)E & SKDS(T/A)ASTE & - & ND \\
Non-repeat region & - & $80 \%$ & $81 \%$ & $84 \%$ \\
Repeat 2 & SNSQSASTSA & ANSQSASTST & ANSQSASTSTSTST & ND \\
Repeat 3 & SDSAS(V/T)S(A/E) & SDS(T/A)S(V/T)S(A/T) & SXSXSXSX & ND \\
C terminus & - & $87 \%$ & $40 \%$ & $75 \%$
\end{tabular}

Fig. 2. (a) Conserved gene arrangement in a selection of uafB-like loci. Serine-rich repeat genes are coloured red. Genes encoding homologous secretion machinery and glycosylation accessory proteins in different loci are shown in the same colour. The uafB cluster has the same components as the $S$. aureus sraP cluster, but lacks two genes present in the Streptococcus gordonii gspB cluster. (b) Features of the S. saprophyticus MS1146 UafB protein and three staphylococcal UafB homologues. Corresponding features of the different proteins are shown in the same colour. The $\mathrm{N}$ terminus (containing the putative signal peptide), $\mathrm{C}$ terminus (containing the LPXTG sortase motif), non-repeat region and serine-rich repeat regions are indicated. (c) Amino acid identities of the UafB protein with UafB homologues. The repeat sequences represent consensus sequences of the major tandem repeat units. ND, Not determined, because assembled repeat sequences were not available. 
signal peptide, putatively 93 residues in length based on previous analyses of other serine-rich repeat proteins (Bensing et al., 2007). A hydrophobic cell wall-spanning segment at the $\mathrm{C}$ terminus contains an LPETG sortase motif followed by a charged tail. UafB contains three distinct serine-rich tandem repeat regions. The longest of these comprises $68.5 \%$ of the total protein sequence; the three repeat regions together encompass $81.5 \%$ of UafB. Based on studies of other serine-rich repeat proteins, we predicted that the putative binding domain of UafB would reside within the 213-residue non-repeat region between the serine-rich repeat regions. No known conserved protein domains were detected in the non-repeat region sequence, and this region also lacks the corresponding sequence that mediates bacterial cell aggregation recently identified in the Streptococcus pneumoniae PsrP serine-rich repeat protein (Sanchez et al., 2010). The predicted molecular masses of the complete UafB protein and the mature $\mathrm{N}$ - and $\mathrm{C}$-terminally processed $\mathrm{UafB}$ protein are 218.1 and $203.1 \mathrm{kDa}$, respectively.

By searching GenBank for matches to the non-repeat region of UafB, we identified genes encoding UafB homologues, complete with accessory expression system loci, in both Staphylococcus epidermidis and Staphylococcus haemolyticus. The $42.6 \mathrm{~kb}$ S. epidermidis SK30 plasmid SAP107a (GenBank accession no. GQ900456.1) contains a gene encoding a 2681-residue serine-rich repeat protein which is homologous to $\mathrm{UafB}$, but has been misannotated as two individual genes, namely $s d r I$ and $f l i K$. Additionally, we detected sequences representing the $\mathrm{N}$ terminus, nonrepeat region, $\mathrm{C}$ terminus and accessory expression genes of a UafB homologue in the draft genome of $S$. epidermidis W23144 (GenBank accession no. ACJC00000000; ZP_ 04797573.1, ZP_04797572.1, NZ_ACJC01000147). Each of these sequence fragments is located at the very beginning of a separate contig and it is apparent that these contigs have not yet undergone final assembly. Based on the draft assembly, it is not clear whether this putative $u a f B$ homologue is chromosomally or plasmid located. Gene SH0326 (GenBank accession no. 3484004) of the sequenced S. haemolyticus JCSC1435 strain encodes a 3607-residue UafB homologue protein which is followed by accessory expression system genes.

The closest matches to the S. saprophyticus UafB nonrepeat region are from the above-mentioned coagulasenegative staphylococci (Fig. 3a). The amino acid identity of each section of the S. saprophyticus MS1146 UafB protein with the S. epidermidis and S. haemolyticus homologues is shown in Fig. 2(c). The S. epidermidis UafB homologues have good matches to each of the UafB subsequences, including the serine-rich repeat units (note that no repeat sequence data are available for S. epidermidis W23144). All three UafB homologues share high amino acid similarity $(\geqslant 80 \%)$ with the non-repeat region of UafB (Fig. $2 \mathrm{c}$ and Fig. 3b), which contains the predicted ligand-binding residues. While having an $81 \%$ identity with the UafB nonrepeat region, the S. haemolyticus homologue protein termini and serine-rich repeats are noticeably more divergent. The accessory protein sequences (concatenated) of the S. epidermidis homologues also share high similarity with the corresponding UafB sequence (SAP107a, 91\%; W23144, 95\%), while the concatenated S. haemolyticus accessory proteins share $58 \%$ similarity (data not shown). A number of transposase sequences are present in close proximity to the uafB-like loci in S. haemolyticus JCSC1435 and in the S. epidermidis SK30 SAP107a plasmid. A comparison of S. saprophyticus pSSAP1 and S. epidermidis SAP107a plasmids revealed that apart from genes encoding the serine-rich repeat and accessory expression proteins, only transposase genes and a malate:quinone oxidoreductase gene were shared. Of note, pSSAP1 contains one copy of IS431 located downstream of the uafB locus compared with three copies of IS431 downstream of the uafB homologue locus in SAP107a.

\section{UafB contributes to cell surface hydrophobicity}

To evaluate the putative role of $\mathrm{UafB}$ on cell surface hydrophobicity, we constructed a uafB knockout mutant employing the TargeTron system (Sigma). The correct isogenic uafB knockout (referred to as MS1146uafB) was verified by colony PCR and sequencing, as well as PCR screening for the S. saprophyticus MS1146 endogenous plasmids to ensure that none had been lost in the process. The hydrophobicity indices of S. saprophyticus MS1146, MS1146uafB and MS2827 were compared by examining adhesion to n-hexadecane. In comparison with S. saprophyticus MS1146, MS1146uafB and MS2827 displayed a $44 \%$ decrease in cell surface hydrophobicity in this assay $(P=0.001$; Fig. 1a). Thus, UafB is a major contributor to the cell surface hydrophobicity of S. saprophyticus MS1146, and the generation of a specific $u a f B$ deletion strain confirms the contribution of UafB in the PSSAP1 plasmidcured strain MS2827.

\section{Prevalence of uafB in S. saprophyticus}

To assess the prevalence of uafB in S. saprophyticus we screened a collection of 76 clinical isolates from three different locations. The isolates were screened for the presence of the $u a f B$ gene, as well as the two previously described LPXTG motif-containing adhesin genes of $S$. saprophyticus (i.e. uafA and sdrI). PCR screening detected uafB in $5.3 \%(4 / 76)$ of the S. saprophyticus strains, uafA in $100 \%(76 / 76)$ and $s d r I$ in $6.6 \%(5 / 76)$. Southern blotting confirmed the uafB prevalence result (data not shown). None of the strains harboured both $u a f B$ and $s d r I$.

\section{UafB is a glycoprotein expressed by $S$. saprophyticus MS1146}

Examination of whole-cell lysates prepared from $S$. saprophyticus MS1146, MS1146uafB and MS2827 by SDSPAGE and Western blotting employing a UafB-specific antiserum (directed at amino acid residues 72-506) 
(a)

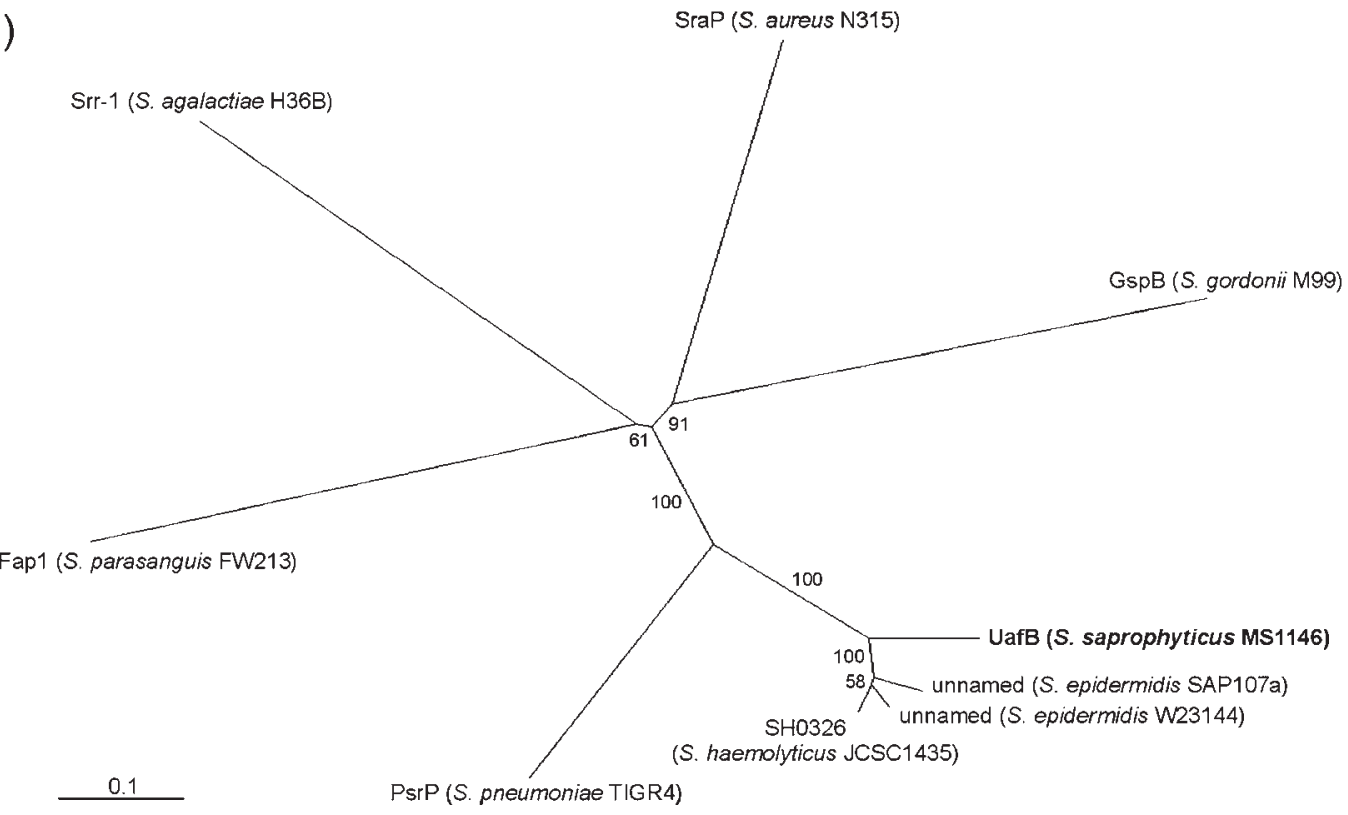

(b)

\begin{tabular}{|c|c|c|}
\hline \multirow{4}{*}{\multicolumn{3}{|c|}{$\begin{array}{l}\text { UafB (S. saprophyticus) } \\
\text { Unnamed (S. epidermidis plasmid SAP107a) } \\
\text { Unnamed (S. epidermidis W23144) } \\
\text { SH0326 (S. haemolyticus JCSC 1435) }\end{array}$}} \\
\hline & & \\
\hline & & \\
\hline & & \\
\hline & $(S$. & \\
\hline inamed & $d(S$. & mid SAF \\
\hline 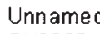 & $d(S$ & epidermidi \\
\hline & & haem \\
\hline & $(S$. & sapre \\
\hline 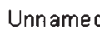 & (S & epiderm \\
\hline & & epide \\
\hline & & \\
\hline afB & $(S$. & \\
\hline Innamed & $d(S$. & epidermidis plasm \\
\hline Jnn & $d(S$. & epidermidis Wh \\
\hline & & haemolyticus JCSC 1435) \\
\hline AID & & \\
\hline & & epidermidis plas \\
\hline $\mathrm{nn}$ & & ider \\
\hline
\end{tabular}

DLGSAIVTNDDSDSSSNSTSAIELRTFSRLATTTFATA---STTNTYTGAG 47

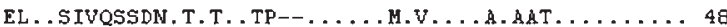

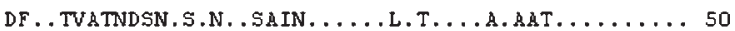
DL. . TLLVSDST. T. T. APLK..... . T...A.AAT....... 50 TD TNNN IP I YYKL TTVNNGTS MTFTYTVTYDNP \& TTTVEKPTTLTNNYSI 97

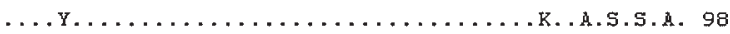

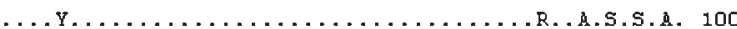
...Y................................. 100

YNTGTSYQTMFTLGNGYGTPSSATSYITDSTGAKVSNPABGTTSMVQQGG 147 $\ldots \ldots$ TY.P....SR....T. . . . . . . . .R.N..NINK..S 148 .... TN.T. . . SA.... T. . . . . . Q...R.N..NINK..S 150 ....TN. T. . . SA.... T. . . . . . . . R.N..NINK. .S 150 GYTUANGYOMNGYQAKQGYGL TTTWTAP INSGGDKSF TF DPYSTSUTGGT 197 $\ldots \ldots \ldots \ldots$. . . . . . . . . . . . . . . . . . . . . 198 $\ldots \ldots \ldots \ldots \ldots$........................... 200 .................................. 200

DFFNGQKVTVTDPT 211

N...Q...... 212

N...Q...... 214

N...K...... 214

Fig. 3. Comparison of non-repeat regions of UafB and UafB homologues. (a) Unrooted phylogram produced from a CLUSTAL W alignment of the non-repeat regions of staphylococcal and streptococcal serine-rich repeat proteins, using the neighbourjoining algorithm implemented under CLUSTAL X. UafB clusters with homologues from S. epidermidis and S. haemolyticus. Bootstrap values out of 100 are indicated. Distance is measured in substitutions per site. S. saprophyticus UafB is shown in bold type. (b) CLUSTAL W alignment of the non-repeat regions of UafB and its staphylococcal homologues, showing high amino acid sequence conservation. Residues identical to the $S$. saprophyticus UafB sequence are denoted with a dot. Residue positions relative to the start of the serine-rich repeat protein sequences are as follows: S. saprophyticus MS1146 UafB, 334544; S. epidermidis plasmid SAP107a, 359-570; S. haemolyticus JCSC1435, 284-497. Proportions of hydrophobic and polar/charged residues of the non-repeat regions are consistent amongst the homologues and are as follows (hydrophobic, polar/charged): S. saprophyticus MS1146 UafB, $31 \%, 55 \%$; S. epidermidis plasmid SAP107a, $32 \%, 55 \%$; S. haemolyticus JCSC1435, 33\%, $55 \%$; S. epidermidis W23144, 33\%, $55 \%$.

demonstrated expression of $\mathrm{UafB}$ in $S$. saprophyticus MS1146 but not in MS1146uafB or MS2827 (Fig. 4a). The apparent molecular mass of UafB was $>460 \mathrm{kDa}$, significantly larger than its expected molecular mass of $203.1 \mathrm{kDa}$. DIG glycan analysis detected a high-molecularmass band for S. saprophyticus MS1146 but not for the 
(a)
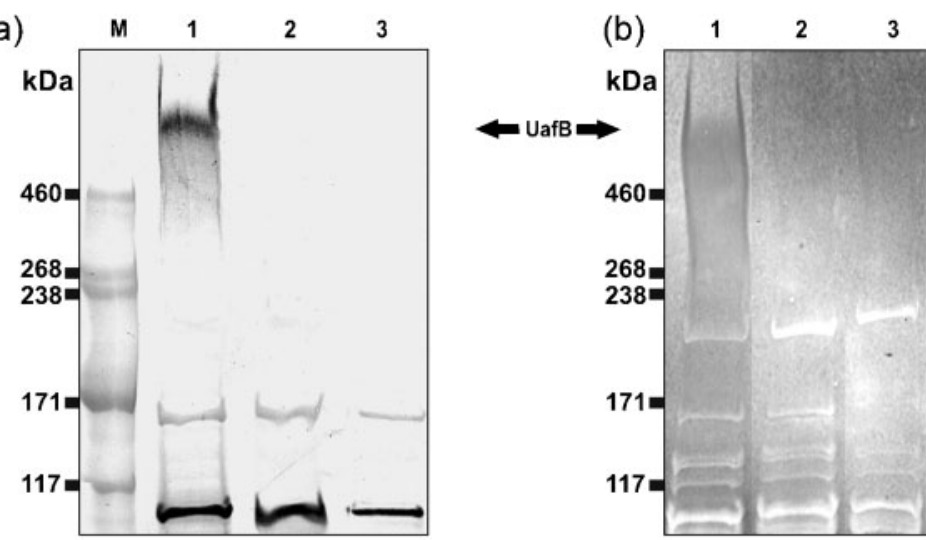

(c)

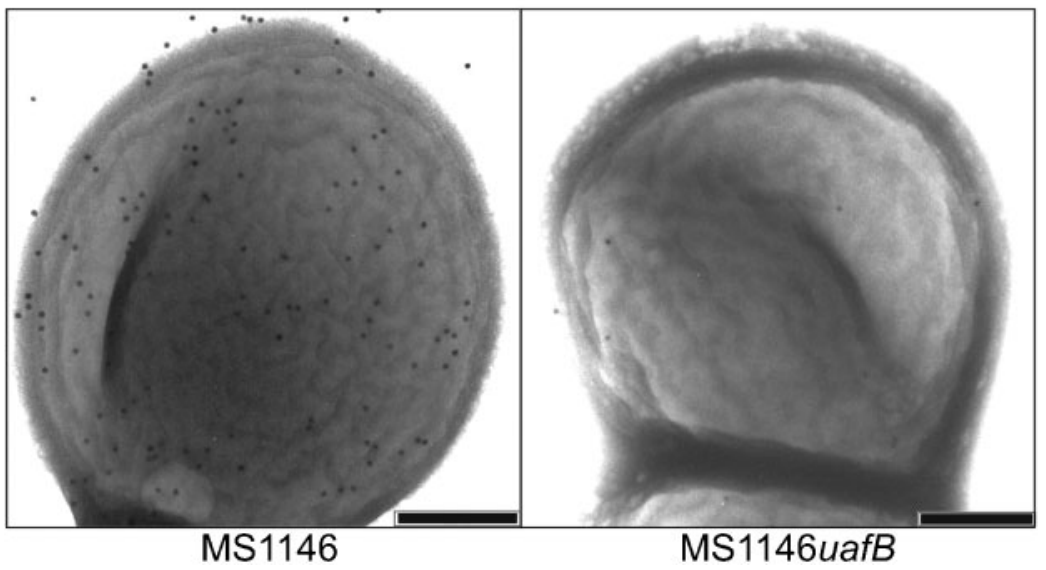

Fig. 4. Expression of UafB. (a) Western blot analysis of whole-cell lysates prepared from $S$. saprophyticus MS1146, MS1146uafB and MS2827 using a polyclonal antiserum directed against UafB. Lanes: M, HiMark prestained protein marker (Invitrogen); 1, MS1146; 2, MS1146uafB; 3, MS2827. Expression of UafB was detected in wild-type $S$. saprophyticus strain MS1146 but not in its isogenic uafB mutant or the pSSAP1 plasmid-cured mutant. The lower-molecular-mass bands common to all strains are not related to UafB. (b) Carbohydrate analysis of total cell lysates prepared from S. saprophyticus MS1146, MS1146uafB and MS2827 using a DIG Glycan Detection kit (Roche). Lanes: 1, MS1146; 2, MS1146uafB; 3, MS2827. A high-molecular-mass band was detected in wild-type S. saprophyticus strain MS1146 but not in its isogenic uafB mutant or the pSSAP1 plasmid-cured mutant. A positive control of human salivary glycoproteins was used and reacted strongly in this assay (data not shown). (c) Immunogold TEM of $S$. saprophyticus MS1146 and MS1146uafB. Expression of UafB at the cell surface of $S$. saprophyticus MS1146 was demonstrated by abundant labelling with UafB-gold particles. In contrast, S. saprophyticus MS1146uafB was virtually devoid of gold labelling. Bars, $200 \mathrm{~nm}$.
MS1146uafB and MS2827 mutants (Fig. 4b). This band corresponds to the UafB band detected by Western blotting and shows that UafB is glycosylated.

\section{UafB is located at the cell surface}

The salient features of UafB suggest that it is covalently anchored to the cell wall and exposed at the cell surface. To confirm this, we used the UafB-specific antiserum for immunogold labelling and electron microscopy of $S$. saprophyticus MS1146. Wild-type S. saprophyticus MS1146 cells displayed abundant surface labelling with UafB-gold particles. In contrast, S. saprophyticus MS1146uafB and MS2827 (data not shown) were devoid of labelling with UafB-specific antibodies (Fig. 4c). These data show that the $u a f B$ gene is functional and results in the expression of a large protein at the cell surface in S. saprophyticus MS1146.

\section{UafB mediates binding to bladder epithelial cells, fibronectin and fibrinogen}

The contribution of UafB to adhesion to human T24 bladder epithelial cells was examined. We observed an eightfold reduction in binding to T24 bladder epithelial cells by the $S$. saprophyticus MS1146uafB and MS2827 mutants compared with S. saprophyticus MS1146 ( $P<0.001$; Fig. 5a). Recently, we have shown that $\mathrm{T} 24$ bladder cells contain a high amount of fibronectin (Valle et al., 2008), and thus we also examined the ability of UafB to mediate binding to this ECM protein. In contrast to wild-type S. saprophyticus MS1146 cells, MS1146uafB and MS2827 adhered significantly less to fibronectin $(P<0.001$; Fig. 5b), demonstrating the involvement of UafB in this adhesion phenotype. We also found that UafB bound to fibrinogen $(P<0.001$; Fig. $5 \mathrm{~b})$. To examine the specificity of binding to fibronectin and fibrinogen, we also tested S. saprophyticus MS1146 for its ability to bind to other ECM proteins. S. saprophyticus MS1146 did not adhere to laminin, collagen I, collagen II, collagen IV or vitronectin (data not shown).

\section{The non-repeat region of UafB mediates binding to both fibronectin and fibrinogen}

To further characterize the binding of UafB to its receptors we sought to determine whether the non-repeat region of the protein contained the binding domain. To facilitate these experiments, the non-repeat region of UafB was PCRamplified, cloned, expressed and purified as a fusion to the thioredoxin scaffold sequence. Using an ELISA approach, we found that the non-repeat region of UafB binds to both fibronectin and fibrinogen. The control recombinant protein lacking the UafB sequence (i.e. thioredoxin alone) bound significantly less in both cases $(P<0.001$; Fig. 5 c). Neither recombinant protein bound to BSA. 


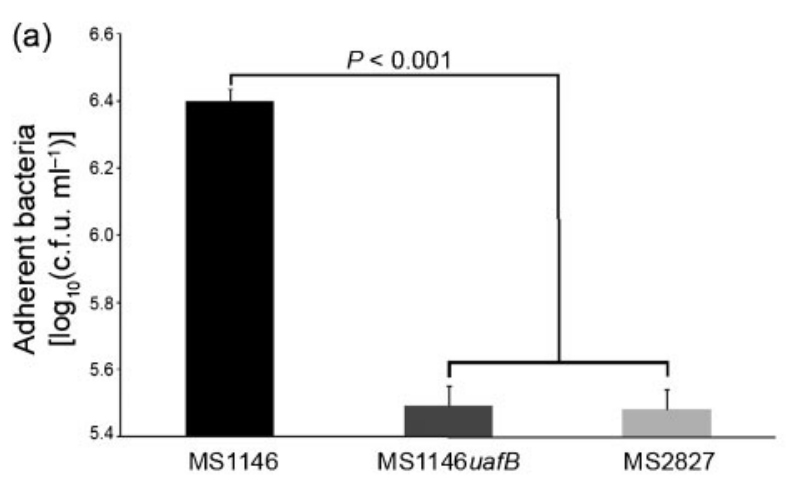

(b)

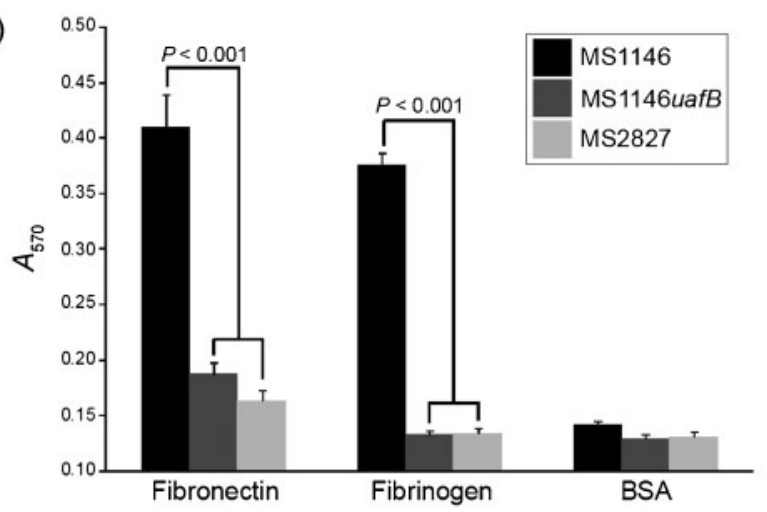

(c)

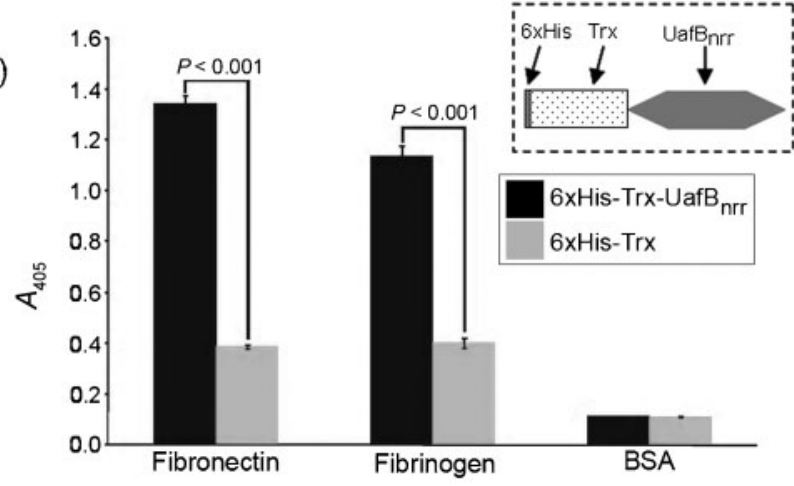

\section{The uafB gene does not contribute to colonization of the mouse bladder}

To study the role of $\mathrm{UafB}$ in virulence we examined the ability of S. saprophyticus MS1146, MS1146uafB and MS2827 to colonize the mouse urinary tract. The mouse UTI model is well established for uropathogenic E. coli (UPEC), and has been used successfully to define the role of several virulence factors (Connell et al., 1996; Ulett et al., 2007b). S. saprophyticus MS1146 efficiently colonized the mouse bladder $\left[8.8 \times 10^{5}\right.$ c.f.u. $\left.\mathrm{ml}^{-1}(0.1 \mathrm{~g} \text { bladder tissue })^{-1}\right]$; this level of colonization is similar to that which we routinely observe for the UPEC strain CFT073 (Ulett et al., 2007b; Valle et al., 2008). However, S. saprophyticus MS1146uafB and MS2827 also colonized the mouse bladder with equal efficiency $\left[8.3 \times 10^{5}\right.$ and $8.0 \times 10^{5}$ c.f.u. $\mathrm{ml}^{-1}(0.1 \mathrm{~g}$ bladder tissue $)^{-1}$, suggesting that UafB does not affect adhesion in this infection model. A similar level of colonization was also
Fig. 5. (a) Adhesion of S. saprophyticus MS1146, MS1146uafB and MS2827 to human T24 bladder epithelial cells. T24 bladder epithelial cell monolayers were inoculated with bacteria and incubated for $80 \mathrm{~min}$ at $37^{\circ} \mathrm{C}$, and adherent bacteria were enumerated by direct plating and colony counts. Results are the mean + SEM of eight replicates from three independent experiments. A significant difference in adhesion was observed between MS1146 and MS1146uafB/MS2827 ( $P<0.001$; ANOVA). (b) Adhesion of $S$. saprophyticus MS1146, MS1146uafB and MS2827 to immobilized fibronectin and fibrinogen. Cell suspensions of each strain were added to microtitre plate wells coated with fibronectin, fibrinogen and BSA (negative control) and incubated for $2 \mathrm{~h}$ at $37^{\circ} \mathrm{C}$. Adherent bacteria were stained with $0.1 \%$ crystal violet and quantified by $A_{570}$. Data represent the mean + SEM of 12 replicates from three independent experiments. Significant differences in adhesion to fibronectin and fibrinogen were observed between MS1146 and MS1146uafB/MS2827 $(P<0.001 ;$ ANOVA). (c) Direct binding of the recombinant UafB non-repeat region to fibronectin and fibrinogen. Microtitre plate wells coated with fibronectin, fibrinogen or BSA were incubated with recombinant $6 \times \mathrm{His}-\mathrm{UafB}$ non-repeat region thioredoxin fusion or $6 \times$ His-thioredoxin proteins at $37^{\circ} \mathrm{C}$ for $1 \mathrm{~h}$. A schematic representation of the recombinant $6 \times \mathrm{His}-\mathrm{Trx}-\mathrm{UafB} \mathrm{B}_{\text {nrr }}$ protein is shown in the inset. Detection was performed using antipolyhistidine antibodies. Following $30 \mathrm{~min}$ development, $A_{405}$ was read with a microtitre plate reader. Data represent the mean + SEM of three replicates from three independent experiments. The recombinant protein containing the UafB non-repeat region adhered to both fibronectin $(P<0.001)$ and fibrinogen $(P<0.001)$ significantly more than the thioredoxin-only control protein $(t$ test).

observed in the urine of infected mice, while no significant colonization of the kidneys was observed (data not shown).

\section{UafB promotes specific adhesion to human uroepithelial cells}

The above results suggest that UafB may mediate differential binding to human and mouse bladder cells. To investigate this further, we examined the ability of $S$. saprophyticus MS1146, MS1146uafB and MS2827 to bind to exfoliated uroepithelial cells freshly harvested from human urine. S. saprophyticus MS1146 mediated very strong binding to these cells, while $S$. saprophyticus MS1146uafB and MS2827 did not adhere (Fig. 6). Thus, UafB appears to be an adhesin specifically associated with adherence to human bladder epithelial cells.

\section{DISCUSSION}

S. saprophyticus is a common cause of community-acquired UTI, especially among the sexually active young female demographic. However, surprisingly little is known about the molecular mechanisms that underpin the ability of $S$. saprophyticus to cause infection, with only a handful of molecular genetic studies undertaken to date. Acknowledged 
virulence factors include urease (Gatermann \& Marre, 1989), a cell surface lipase (Sakinç et al., 2005), slime production (Atmaca et al., 2000), cell surface hydrophobicity (Schneider \& Riley, 1991) and three adhesins (Aas, UafA and SdrI) (Hell et al., 1998; Kuroda et al., 2005; Sakinç et al., 2006). S. saprophyticus strains are known to bind collagen (Sakinç et al., 2006), laminin (Paulsson et al., 1992) and fibronectin (Gatermann \& Meyer, 1994). Here we have identified a novel plasmid-located gene in S. saprophyticus MS1146 which we have termed uro-adherence factor B (uafB). The uafB gene is the third LPXTG motif-encoding $S$. saprophyticus gene described to date.

UafB is a cell wall-anchored adhesin that belongs to a group of serine-rich repeat surface proteins that are dependent on a proprietary export system for glycosylation and transport across the cell membrane; it is the first such protein identified in S. saprophyticus. Serine-rich repeat proteins have been identified from other staphylococci, streptococci and a lactobacillus. A locus of core genes encoding SecA2, SecY2, three accessory secretory proteins and two glycosyltransferases is located immediately downstream of the $u a f B$ gene. The $u a f B$ cluster lacks the $g l y$ and $n s s$ genes present in the Streptococcus gordonii gspB cluster [consistent with all other known staphylococcal serine-rich repeat protein accessory loci (Zhou \& Wu, 2009)], but still produces a functional adhesive glycoprotein. The UafB atypical signal sequence contains the key glycine residues and conserved KSGKXW motif (Bensing et al., 2007) that are present in the signal sequences of other members of the serine-rich repeat protein family.

Searches for other proteins with non-repeat regions similar to those of $U$ afB resulted in the identification of a chromosomal homologue in S. haemolyticus, a previously misannotated homologue on an S. epidermidis plasmid and a putative homologue in an S. epidermidis draft genome. S. epidermidis and S. haemolyticus are commensal coagulasenegative staphylococci that tend to cause opportunistic infections, especially in the immunocompromised. Interestingly, both S. epidermidis and S. haemolyticus can also cause UTIs. The finding that $u a f B$ cluster homologues are found in other staphylococci suggests that uafB is not just a rare $S$. saprophyticus adhesion factor, and the presence of the nearby transposase sequences is strong evidence that the $u a f B$ and $u a f B$-like loci were once part of mobile elements. Indeed, our sequence data suggest that the $u a f B$ cluster was mobilized en bloc onto PSSAP1 via transposition.

Cell surface hydrophobicity represents an important virulence determinant in bacterial urinary pathogens, including coagulase-negative staphylococci (Martin et al., 1989). Hydrophobic forces contribute to the initial events that lead to irreversible adhesion of bacteria to a surface (Arp, 1988), and hydrophobic interactions promote adhesion between bacteria and mammalian cells (Tylewska et al., 1979). Some bacterial cell surface proteins are known to modulate cell surface hydrophobicity. For example, expression of the fibronectin-binding CshA adhesin increases the cell surface hydrophobicity of Streptococcus gordonii (McNab et al., 1999). Here we have demonstrated that UafB is a major cell surface hydrophobicity determinant of S. saprophyticus MS1146.

In order to functionally characterize the UafB protein, we generated two independent mutants. First, we cured the pSSAP1 plasmid from S. saprophyticus MS1146 (whilst maintaining the other two endogenous plasmids), and second an isogenic uafB knockout was constructed by insertional inactivation with a group II intron. To our knowledge, this is the first instance in which the Sigma TargeTron system has been used to generate a gene-specific knockout in S. saprophyticus. For every assay employed in this work, the phenotypes for both of these independent mutants were consistent. We were unable to complement MS1146uafB or MS2827 despite repeated attempts to transform these strains with an E. coli-S. aureus shuttle plasmid (pCU1) containing $u a f B$. The transformation of $S$.

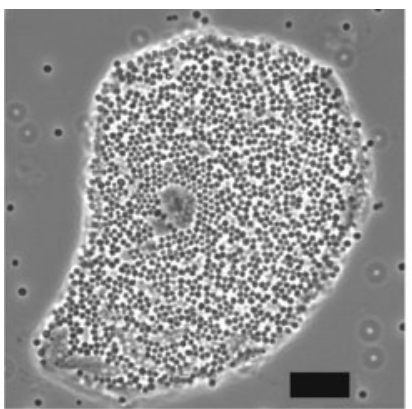

MS1146

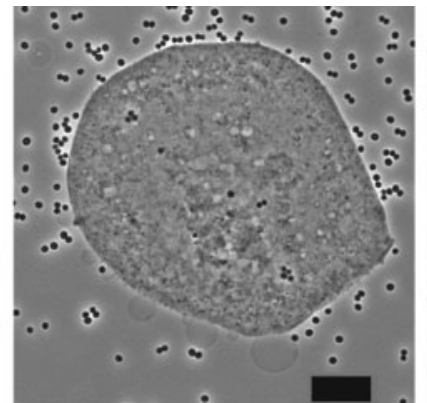

MS1146uafB

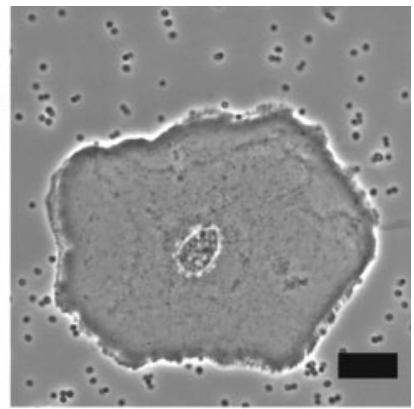

MS2827

Fig. 6. Adhesion of S. saprophyticus MS1146, MS1146uafB and MS2827 to exfoliated human uroepithelial cells. Uroepithelial cells were harvested from fresh pooled human urine, mixed with bacteria and incubated for $1 \mathrm{~h}$ at $37^{\circ} \mathrm{C}$. The cells were visualized by phase-contrast microscopy (×63 magnification). S. saprophyticus MS1146 adhered strongly to uroepithelial cells, while no adhesion was observed for MS1146uafB or MS2827. Bars, $10 \mu \mathrm{m}$. 
saprophyticus requires the generation of protoplasts, and in our hands S. saprophyticus MS1146 is not amenable to transformation with plasmids larger than $10 \mathrm{~kb}$.

S. saprophyticus MS1146, MS1146uafB and MS2827 were used in conjunction with a UafB-specific antiserum to demonstrate that UafB is expressed by $S$. saprophyticus MS1146 and located on the cell surface. The size of the UafB protein identified by Western blot analysis was considerably larger than its expected apparent molecular mass. Since two genes encoding putative glycosyltransferases were identified in the $u a f B$ accessory secretory locus, we hypothesized that this discrepancy in mass may be due to post-translational carbohydrate modification of UafB. We confirmed the glycosylation of UafB using a DIG Glycan Detection kit (Roche). The identity of the modifying glycan residues was not investigated.

S. saprophyticus MS1146 adhered in significantly greater numbers to T24 bladder epithelial cells than the uafBnegative strains MS1146uafB and MS2827. S. saprophyticus strains are known to bind to the ECM proteins collagen (Sakinç et al., 2006), laminin (Paulsson et al., 1992) and fibronectin (Gatermann \& Meyer, 1994), and thus we also examined the adherence of these strains to a range of ECM molecules. Our data show that UafB plays a role in the binding of S. saprophyticus MS1146 to immobilized fibronectin. The background fibronectin binding by MS1146uafB and MS2827 is likely due to the Aas protein. Fibronectin is a large dimeric glycoprotein that is present in both its soluble and cellular forms in the ECM of epithelial cells. Numerous fibronectin-binding adhesins from Gram-positive bacteria have been characterized, including Fba proteins, Sfb proteins and M1 protein from Streptococcus pyogenes; FnBA and FnBB from Streptococcus dysgalactiae; PavA from Streptococcus pneumoniae; FbpA and CshA from Streptococcus gordonii; FnBPA and FnBPB from S. aureus and Aas and SdrI from $S$. saprophyticus (Henderson et al., 2011; Sakinç et al., 2009). Binding of epithelial cell fibronectin can also lead to invasion by pathogenic staphylococci and streptococci (Joh et al., 1999). Future work will investigate whether $\mathrm{UafB}$ is involved in internalization of $S$. saprophyticus MS1146 in uroepithelial cells. A number of bacterial fibronectin-binding adhesins, such as FnBPA of S. aureus and SfbI of Streptococcus pyogenes, can also bind fibrinogen, a soluble plasma glycoprotein. The fibronectin- and fibrinogen-binding domains of these adhesins are typically located at separate termini of the protein, unlike UafB, in which the N-terminal non-repeat region mediates adhesion to both receptors. Most, but not all, serine-rich repeat proteins are lectins; this has not yet been established for UafB. Due to the strong similarity between the non-repeat regions of $\mathrm{UafB}$ and those of its homologues, we speculate that these homologues may share binding specificities with UafB. Adhesins recognizing fibronectin and fibrinogen have been identified and characterized in S. epidermidis, but functional redundancy is also well established for bacterial adhesins. S. haemolyticus is known to bind fibronectin, among other host proteins (Paulsson et al.,
1992), but very little is known about the mechanisms of adhesion of this species.

The UafB phenotypic data obtained from the in vitro human cell adhesion experiments were not corroborated in the in vivo mouse UTI model. S. saprophyticus MS1146 efficiently colonized the bladders and urine of the mice, but no role for UafB was apparent. It is possible that this is due to the UafA adhesin, which has been shown to mediate adhesion to human T24 bladder cells in the genomesequenced S. saprophyticus strain ATCC 15305 (Kuroda et al., 2005). However, further work is required to confirm this and also to evaluate the contribution of the Aas adhesin to S. saprophyticus MS1146 colonization of the mouse bladder. It is possible that the expression of redundant adhesins disguises the phenotype of UafB in the mouse UTI model. The lack of mouse kidney colonization is in line with previous experiments employing UPEC strains and C57BL/6 mice in our laboratory (Ulett et al., 2007b; Valle et al., 2008).

Other studies have demonstrated that S. saprophyticus exhibits a higher level of adhesion to uroepithelial cells than other types of epithelia, including buccal and skin epithelial cells (Colleen et al., 1979; Mårdh et al., 1979), and almost exclusively causes infections of the urinary tract. Although S. saprophyticus can colonize the murine urinary tract, the lack of UafB-mediated adhesion in the mouse model prompted us to examine its ability to mediate adherence to freshly harvested human uroepithelial cells. We observed a striking difference in adherence between S. saprophyticus MS1146 and the uafB-negative strains MS1146uafB and MS2827, suggesting the possibility that UafB surface expression mediates tropism for human uroepithelial cells. The precise mechanism by which UafB binds to uroepithelial cells remains to be determined.

The S. saprophyticus uafB prevalence (5.3\%) in this study is comparable with that of the $s d r I$ gene $(6.6 \%)$ for the same collection of strains. Importantly, uafB-positive S. saprophyticus strains were identified amongst clinical isolates collected from both Australia and the USA. Further work needs to be done to assess the prevalence of the uafB homologues in S. epidermidis and S. haemolyticus clinical isolates, and to study their functions. It also remains to be seen whether uafB is exclusively plasmid-encoded in uafBpositive S. saprophyticus strains. However, the plasmid location of $u a f B$, together with the fact that homologous uafB loci are located on apparently transposable elements in other staphylococci, suggests the possibility that this adherence-encoding factor is mobile and can be spread between different species of staphylococci.

\section{ACKNOWLEDGEMENTS}

This work was supported by grants from the Australian National Health and Medical Research Council to M. A. S. (455914) and S. A. B. (511224), and a University of Queensland Early Career Researcher grant to S.A.B. M.A.S. is supported by an Australian Research Council (ARC) Future Fellowship (FT100100662) and S.A.B. is 
supported by an ARC Australian Research Fellowship (DP0881247). We would like to thank Türkan Sakinç for expert advice on procedures for transformation of S. saprophyticus, and Kathy MacCormick and Bob McLaughlin from AstraZeneca for expert technical assistance.

\section{REFERENCES}

Altschul, S. F., Madden, T. L., Schäffer, A. A., Zhang, J. H., Zhang, Z., Miller, W. \& Lipman, D. J. (1997). Gapped BLAST and PSI-BLAST: a new generation of protein database search programs. Nucleic Acids Res 25, 3389-3402.

Arp, L. H. (1988). Bacterial infection of mucosal surfaces: an overview of cellular and molecular mechanisms. In Virulence Mechanisms of Bacterial Pathogens, pp. 6-8. Edited by J. A. Roth. Washington, DC: Americal Society for Microbiology.

Atmaca, S., Elci, S. \& Akpolat, N. O. (2000). Differential production of slime by Staphylococcus saprophyticus under aerobic and anaerobic conditions. J Med Microbiol 49, 1051-1052.

Bensing, B. A. \& Sullam, P. M. (2009). Characterization of Streptococcus gordonii SecA2 as a paralogue of SecA. J Bacteriol 191, 3482-3491.

Bensing, B. A., Gibson, B. W. \& Sullam, P. M. (2004a). The Streptococcus gordonii platelet binding protein GspB undergoes glycosylation independently of export. J Bacteriol 186, 638-645.

Bensing, B. A., López, J. A. \& Sullam, P. M. (2004b). The Streptococcus gordonii surface proteins GspB and Hsa mediate binding to sialylated carbohydrate epitopes on the platelet membrane glycoprotein Ib $\alpha$. Infect Immun 72, 6528-6537.

Bensing, B. A., Siboo, I. R. \& Sullam, P. M. (2007). Glycine residues in the hydrophobic core of the GspB signal sequence route export toward the accessory Sec pathway. J Bacteriol 189, 3846-3854.

Chen, Q., Wu, H., Kumar, R., Peng, Z. X. \& Fives-Taylor, P. M. (2006). $\mathrm{SecA} 2$ is distinct from SecA in immunogenic specificity, subcellular distribution and requirement for membrane anchoring in Streptococcus parasanguis. FEMS Microbiol Lett 264, 174-181.

Colleen, S., Hovelius, B., Wieslander, A. \& Mårdh, P. A. (1979). Surface properties of Staphylococcus saprophyticus and Staphylococcus epidermidis as studied by adherence tests and two-polymer, aqueous phase systems. Acta Pathol Microbiol Scand [B] 87, 321-328.

Connell, I., Agace, W., Klemm, P., Schembri, M., Mărild, S. \& Svanborg, C. (1996). Type 1 fimbrial expression enhances Escherichia coli virulence for the urinary tract. Proc Natl Acad Sci U S A 93, 98279832.

Endo, G. \& Silver, S. (1995). CadC, the transcriptional regulatory protein of the cadmium resistance system of Staphylococcus aureus plasmid pI258. J Bacteriol 177, 4437-4441.

Faro, S. \& Fenner, D. E. (1998). Urinary tract infections. Clin Obstet Gynecol 41, 744-754.

Foxman, B., Gillespie, B., Koopman, J., Zhang, L., Palin, K., Tallman, P., Marsh, J. V., Spear, S., Sobel, J. D. \& other authors (2000). Risk factors for second urinary tract infection among college women. Am J Epidemiol 151, 1194-1205.

Gatermann, S. \& Marre, R. (1989). Cloning and expression of Staphylococcus saprophyticus urease gene sequences in Staphylococcus carnosus and contribution of the enzyme to virulence. Infect Immun 57, 2998-3002.

Gatermann, S. \& Meyer, H. G. W. (1994). Staphylococcus saprophyticus hemagglutinin binds fibronectin. Infect Immun 62, 4556-4563.

Gordon, D., Abajian, C. \& Green, P. (1998). Consed: a graphical tool for sequence finishing. Genome Res 8, 195-202.
Grant, S. G. N., Jessee, J., Bloom, F. R. \& Hanahan, D. (1990). Differential plasmid rescue from transgenic mouse DNAs into Escherichia coli methylation-restriction mutants. Proc Natl Acad Sci U S A 87, 4645-4649.

Hell, W., Meyer, H. G. W. \& Gatermann, S. G. (1998). Cloning of aas, a gene encoding a Staphylococcus saprophyticus surface protein with adhesive and autolytic properties. Mol Microbiol 29, 871-881.

Henderson, B., Nair, S., Pallas, J. \& Williams, M. A. (2011). Fibronectin: a multidomain host adhesin targeted by bacterial fibronectin-binding proteins. FEMS Microbiol Rev 35, 147-200.

Hooton, T. M. \& Stamm, W. E. (1997). Diagnosis and treatment of uncomplicated urinary tract infection. Infect Dis Clin North Am 11, 551-581.

Hovelius, B. \& Mårdh, P. A. (1984). Staphylococcus saprophyticus as a common cause of urinary tract infections. Rev Infect Dis 6, 328-337.

Joh, D., Wann, E. R., Kreikemeyer, B., Speziale, P. \& Höök, M. (1999). Role of fibronectin-binding MSCRAMMs in bacterial adherence and entry into mammalian cells. Matrix Biol 18, 211-223.

Kleine, B., Gatermann, S. \& Sakinç, T. (2010). Genotypic and phenotypic variation among Staphylococcus saprophyticus from human and animal isolates. BMC Res Notes 3, 163.

Kuroda, M., Yamashita, A., Hirakawa, H., Kumano, M., Morikawa, K., Higashide, M., Maruyama, A., Inose, Y., Matoba, K. \& other authors (2005). Whole genome sequence of Staphylococcus saprophyticus reveals the pathogenesis of uncomplicated urinary tract infection. Proc Natl Acad Sci U S A 102, 13272-13277.

Mårdh, P. A., Colleen, S. \& Hovelius, B. (1979). Attachment of bacteria to exfoliated cells from the urogenital tract. Invest Urol 16, 322-326.

Martin, M. A., Pfaller, M. A., Massanari, R. M. \& Wenzel, R. P. (1989). Use of cellular hydrophobicity, slime production, and species identification markers for the clinical significance of coagulasenegative staphylococcal isolates. Am J Infect Control 17, 130-135.

McCrea, K. W., Hartford, O., Davis, S., Eidhin, D. N., Lina, G., Speziale, P., Foster, T. J. \& Höök, M. (2000). The serine-aspartate repeat (Sdr) protein family in Staphylococcus epidermidis. Microbiology 146, 1535-1546.

McNab, R., Forbes, H., Handley, P. S., Loach, D. M., Tannock, G. W. \& Jenkinson, H. F. (1999). Cell wall-anchored CshA polypeptide (259 kilodaltons) in Streptococcus gordonii forms surface fibrils that confer hydrophobic and adhesive properties. J Bacteriol 181, 3087-3095.

Navarre, W. W. \& Schneewind, O. (1999). Surface proteins of Grampositive bacteria and mechanisms of their targeting to the cell wall envelope. Microbiol Mol Biol Rev 63, 174-229.

Nucifora, G., Chu, L., Misra, T. K. \& Silver, S. (1989). Cadmium resistance from Staphylococcus aureus plasmid pI258 cadA gene results from a cadmium-efflux ATPase. Proc Natl Acad Sci U S A 86, 3544-3548.

Paulsson, M., Ljungh, A. \& Wadström, T. (1992). Rapid identification of fibronectin, vitronectin, laminin, and collagen cell surface binding proteins on coagulase-negative staphylococci by particle agglutination assays. J Clin Microbiol 30, 2006-2012.

Peng, Z., Wu, H., Ruiz, T., Chen, Q., Zhou, M., Sun, B. \& Fives-Taylor, P. (2008). Role of gap3 in Fap1 glycosylation, stability, in vitro adhesion, and fimbrial and biofilm formation of Streptococcus parasanguinis. Oral Microbiol Immunol 23, 70-78.

Rupp, M. E. \& Archer, G. L. (1994). Coagulase-negative staphylococci: pathogens associated with medical progress. Clin Infect Dis 19, 231243, quiz 244-245.

Rupp, M. E., Soper, D. E. \& Archer, G. L. (1992). Colonization of the female genital tract with Staphylococcus saprophyticus. J Clin Microbiol 30, 2975-2979. 
Rutherford, K., Parkhill, J., Crook, J., Horsnell, T., Rice, P., Rajandream, M. A. \& Barrell, B. (2000). Artemis: sequence visualization and annotation. Bioinformatics 16, 944-945.

Sakinç, T., Woznowski, M., Ebsen, M. \& Gatermann, S. G. (2005). The surface-associated protein of Staphylococcus saprophyticus is a lipase. Infect Immun 73, 6419-6428.

Sakinç, T., Kleine, B. \& Gatermann, S. G. (2006). SdrI, a serineaspartate repeat protein identified in Staphylococcus saprophyticus strain 7108, is a collagen-binding protein. Infect Immun 74, 46154623.

Sakinç, T., Kleine, B., Michalski, N., Kaase, M. \& Gatermann, S. G. (2009). SdrI of Staphylococcus saprophyticus is a multifunctional protein: localization of the fibronectin-binding site. FEMS Microbiol Lett 301, 28-34.

Sanchez, C. J., Shivshankar, P., Stol, K., Trakhtenbroit, S., Sullam, P. M., Sauer, K., Hermans, P. W. M. \& Orihuela, C. J. (2010). The pneumococcal serine-rich repeat protein is an intra-species bacterial adhesin that promotes bacterial aggregation in vivo and in biofilms. PLoS Pathog 6, e1001044.

Schappert, S. M. (1999). Ambulatory care visits to physician offices, hospital outpatient departments, and emergency departments: United States, 1997. Vital Health Stat 13, 1-36.

Schneider, P. F. \& Riley, T. V. (1991). Cell-surface hydrophobicity of Staphylococcus saprophyticus. Epidemiol Infect 106, 71-75.

Shivshankar, P., Sanchez, C., Rose, L. F. \& Orihuela, C. J. (2009). The Streptococcus pneumoniae adhesin PsrP binds to Keratin 10 on lung cells. Mol Microbiol 73, 663-679.

Siboo, I. R., Chambers, H. F. \& Sullam, P. M. (2005). Role of SraP, a serine-rich surface protein of Staphylococcus aureus, in binding to human platelets. Infect Immun 73, 2273-2280.

Stephenson, A. E., Wu, H., Novak, J., Tomana, M., Mintz, K. \& Fives-Taylor, P. (2002). The Fap1 fimbrial adhesin is a glycoprotein: antibodies specific for the glycan moiety block the adhesion of Streptococcus parasanguis in an in vitro tooth model. Mol Microbiol 43, 147-157.

Takamatsu, D., Bensing, B. A. \& Sullam, P. M. (2004a). Genes in the accessory sec locus of Streptococcus gordonii have three functionally distinct effects on the expression of the platelet-binding protein GspB. Mol Microbiol 52, 189-203.
Takamatsu, D., Bensing, B. A. \& Sullam, P. M. (2004b). Four proteins encoded in the gspB-secY2A2 operon of Streptococcus gordonii mediate the intracellular glycosylation of the platelet-binding protein GspB. J Bacteriol 186, 7100-7111.

Takamatsu, D., Bensing, B. A., Cheng, H., Jarvis, G. A., Siboo, I. R., López, J. A., Griffiss, J. M. \& Sullam, P. M. (2005). Binding of the Streptococcus gordonii surface glycoproteins GspB and Hsa to specific carbohydrate structures on platelet membrane glycoprotein Ib $\alpha$. Mol Microbiol 58, 380-392.

Tylewska, S. K., Hjerten, S. \& Wadstrom, T. (1979). Contribution of $\mathrm{M}$ protein to the hydrophobic surface properties of Streptococcus pyogenes. FEMS Microbiol Lett 6, 249-253.

Ulett, G. C., Mabbett, A. N., Fung, K. C., Webb, R. I. \& Schembri, M. A. (2007a). The role of F9 fimbriae of uropathogenic Escherichia coli in biofilm formation. Microbiology 153, 2321-2331.

Ulett, G. C., Valle, J., Beloin, C., Sherlock, O., Ghigo, J. M. \& Schembri, M. A. (2007b). Functional analysis of antigen 43 in uropathogenic Escherichia coli reveals a role in long-term persistence in the urinary tract. Infect Immun 75, 3233-3244.

Upreti, R. K., Kumar, M. \& Shankar, V. (2003). Bacterial glycoproteins: functions, biosynthesis and applications. Proteomics 3, 363-379.

Valle, J., Mabbett, A. N., Ulett, G. C., Toledo-Arana, A., Wecker, K., Totsika, M., Schembri, M. A., Ghigo, J. M. \& Beloin, C. (2008). UpaG, a new member of the trimeric autotransporter family of adhesins in uropathogenic Escherichia coli. J Bacteriol 190, 4147-4161.

van Sorge, N. M., Quach, D., Gurney, M. A., Sullam, P. M., Nizet, V. \& Doran, K. S. (2009). The group B streptococcal serine-rich repeat 1 glycoprotein mediates penetration of the blood-brain barrier. J Infect Dis 199, 1479-1487.

Wilson, K. (2001). Preparation of Genomic DNA from Bacteria. In Current Protocols in Molecular Biology. Edited by F. M. Ausubel, R. Brent, R. E. Kingston, D. D. Moore, J. G. Seidman, J. A. Smith \& K. Struhl. New York: Wiley.

Wu, H., Mintz, K. P., Ladha, M. \& Fives-Taylor, P. M. (1998). Isolation and characterization of Fap1, a fimbriae-associated adhesin of Streptococcus parasanguis FW213. Mol Microbiol 28, 487-500.

Zhou, M. \& Wu, H. (2009). Glycosylation and biogenesis of a family of serine-rich bacterial adhesins. Microbiology 155, 317-327.

Edited by: J. Lindsay 